\title{
Avaliação do Ensino por Alunos
}

\section{Evaluation of Teaching by Students}

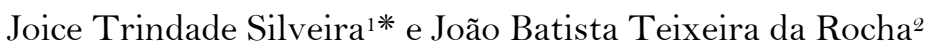 \\ ${ }^{1}$ Universidade Federal do Pampa \\ ${ }^{2}$ Universidade Federal de Santa Maria
}

\begin{abstract}
Este trabalho trata da avaliação do ensino superior pelo viés dos alunos. A partir de análise bibliográfica e documental, discute as abordagens epistemológicas da avaliação educacional, sua situação atual no Brasil e apresenta alguns critérios e modelos utilizados internacionalmente em tais avaliações. O trabalho considera o ensino como a função principal da graduação e a avaliação do ensino pelos alunos como o meio de comunicação destes como o seu curso. No Brasil, o Sistema Nacional de Avaliação do Ensino Superior (SINAES) enfatiza a necessidade da autoavaliação dos cursos de graduação e não define critérios, com o objetivo de que os próprios cursos possam definir suas prioridades e produzir as informações necessárias para a melhoria do ensino. O questionário é a ferramenta predominante quando se avalia um grande número de alunos e há muitos modelos validados que podem subsidiar o trabalho docente. A avaliação do ensino não pode ser dissociada da figura do professor e, quando bem planejada, pode contribuir tanto para o desenvolvimento docente quanto para a qualidade do ensino ministrado dentro das instituições.
\end{abstract}

Palavras-chave: Avaliação de cursos, Métodos de avaliação, Avaliação institucional, Avaliação da atividade docente pelos estudantes.

This work deals with the evaluation of higher education by the bias of the students. From the literature investigation and document analysis, discusses the epistemological approaches to the educational evaluation, its current situation in Brazil and presents some criteria and models used internationally in such assessments. The paper considers education as the main graduation function and evaluation of teaching by students as the way of their communication with its course. In Brazil, the National System of Higer Education Assessment (SINAES) emphasizes to need for self-assessment of courses and does not set criteria for it, for the purpose of the courses themselves define with the object of the courses can define their priorities and produce the necessary information to improve teaching. Questionnaire is the predominant tool when evaluating a large number of students and there are many validated models that can support the teaching. The evaluation of teaching cannot be dissociated from the teacher figure and, when well planned, can contribute to both teacher development and for the quality of education within institutions.

Keywords: Course evaluation, Evaluation criteria, Evaluation method, Institutional evaluation, Student evaluation of teacher performance.

*Contacto: joicetsilveira@gmail.com

issn: $1989-0397$

www.rinace.net/riee/

https://revistas.uam.es/riee
Recibido: $\quad 2$ de junio de 2016

$1^{\text {a }}$ Evaluación: 10 de agosto de 2016

Aceptado: $\quad 1$ de septiembre de 2016 


\section{Introdução}

Nas universidades brasileiras, a avaliação do ensino pelos estudantes ainda é um tema negligenciado. Cada instituição é livre para desenvolver seus métodos e instrumentos e aplicá-los conforme a sua necessidade (SINAES, 2003), porém, na prática, observa-se que essa avaliação ou não tem sido implementada ou não tem produzido os efeitos desejados.

O tema avaliação é sempre polêmico, pois envolve a definição de critérios e métodos que dificilmente são aceitos por todos os envolvidos, principalmente entre os sujeitos avaliados. Diferentemente da avaliação do aluno, em que o professor é o avaliador e o aluno o avaliado, na avaliação do ensino o professor ocupa o lugar de ambos, avaliador e avaliado - visto que não se pode separar a figura do professor da do ensino. Como as práticas entre os docentes possuem uma grande variabilidade, tais critérios de avaliação são de difícil consenso e, muitas vezes, até geram conflitos (Chonko, Tanner e Davis, 2002).

A ausência dessa avaliação do ensino pelos alunos traz consequências para ambos os lados envolvidos. Dos professores, retira a possibilidade de um feedback sobre a sua atividade, ou seja, de saber quais são os seus pontos fortes e onde ou o que precisa ser melhorado na sua prática (Marsh, 1984). Os alunos, por sua vez, também são prejudicados, pois, na ausência de um meio de comunicação com o seu curso, eles não são ouvidos de forma oficial e assim permanecem sem voz durante sua formação (Bobbio, 2012).

Este trabalho teve por objetivo conhecer alguns aspectos que envolvem a avaliação do ensino pelos alunos no âmbito universitário. As perguntas que nortearam a pesquisa foram: Quais são as abordagens epistemológicas da avaliação? Como está a situação da avaliação do ensino no Brasil? Há modelos de avaliação disponíveis? Através das respostas, espera-se contribuir com a atividade de docência e de gestão dentro das universidades.

\section{Abordagens epistemológicas da avaliação}

Historicamente, a avaliação educacional tem sido orientada por dois pressupostos epistemológicos: o positivista e o naturalista. O primeiro, também chamado racionalista ou quantitativo, defende a objetividade e a neutralidade necessárias à ciência. O segundo, também conhecido como subjetivista ou qualitativo, não exige nem objetividade e nem neutralidade absolutas, pois considera a complexidade dos fatores em jogo (Franco, 1990).

O paradigma positivista enfatiza as características observáveis e mensuráveis da avaliação. Considera que um bom instrumento de medida seja essencial para garantir a confiabilidade dos dados (Brandalise, 2010), pois os resultados é que são importantes na pesquisa (Franco, 1990; Herrera, Cano, Hernández y Morales, 2012). Nessa linha, os questionários são predominantes como instrumentos e a avaliação aparece como o resultado de uma série de medições entre o programado e o alcançado. Durante o século $\mathrm{XX}$, estes métodos avaliativos quantitativos predominaram nas avaliações educacionais devido, principalmente, às facilidades relativas ao tratamento dos dados (Sobrinho, 2004). 
As críticas feitas ao modelo quantitativo referem-se à explicação da realidade por uma moral com tendências utilitaristas, pragmáticas e individualistas, onde o progresso seria resultado apenas de uma gestão eficiente: encontrar o problema e resolvê-lo (Sobrinho, 2004). A partir destas críticas surge o paradigma naturalista, que se utiliza de instrumentos como entrevistas e autoavaliações para questionar com maior profundidade, valorizando as situações e os contextos envolvidos em cada avaliação.

Atualmente compreende-se que ambos os paradigmas possuem limitações (Brandalise, 2010). A objetividade é um aspecto importante porque numa avaliação a quantificação e a comparação necessárias só podem ser feitas através de dados objetivos. Não usar dados quantitativos pode levar aos vícios de um subjetivismo exclusivista, onde há relativização de todas as avaliações e ausência de critérios de qualidade, gerando interpretações distorcidas da realidade. Porém, o objetivismo também precisa reconhecer a dimensão social e intersubjetiva do conhecimento, pois não é possível objetividade sem subjetividade, nem quantitativo sem o qualitativo (Sobrinho, 2004).

Um processo avaliativo não deve limitar-se a um único paradigma. Conforme Depresbiteris (2008), a avaliação da educação exige que se combinem vários enfoques, metodologias, instrumentos e estratégias, equilibrando objetividade e subjetividade. Ambas as abordagens devem ser complementares e usadas em função das necessidades do processo avaliativo.

Na prática atual, tem-se optado por utilizar as nomenclaturas somativa e formativa para referir-se aos modelos de avaliação. Em linhas gerais, define-se como somativa a avaliação feita ao final do processo, através de avaliações quantitativas, para que o sujeito avaliado seja classificado. A avaliação formativa, por sua vez, é realizada durante o processo, com características mais qualitativas, para verificar se os objetivos propostos foram alcançados e fazer as interferências necessárias. ${ }^{1}$

\section{A carência de avaliação do ensino no Brasil}

Dentre as diversas atividades que ocorrem dentro da universidade, na graduação o ensino é a principal. $\mathrm{O}$ estudante vai à universidade para aprender algo, como uma ciência ou uma profissão. A sociedade, por sua vez, exige profissionais competentes nas diferentes áreas de atuação. As demais atividades como pesquisa, extensão e gestão funcionam como auxiliares e complementares ao ensino. Nessa situação, a figura do professor é inseparável da atividade de ensino. Seja ele entendido como mediador, facilitador, apresentador de significados ou de novas ideias, a responsabilidade do ensino em cada disciplina do currículo recai sobre o professor. Sua atividade dentro da sala de aula reflete a qualidade deste ensino, da aprendizagem e da interação com os alunos (Morais, Almeida e Montenegro, 2006).

\footnotetext{
${ }^{1}$ Estes termos foram propostos por Scriven (1967), em um trabalho onde o autor desenvolve aspectos da avaliação de currículos, mas assevera que as considerações podem ser transferidas para outras esferas de avaliação. A popularização dos termos, entretanto, deu-se a partir do trabalho de Bloom e colaboradores (1983), intitulado "Manual de Avaliação Formativa e Somativa do aprendizado escolar”. O trabalho de Bloom (1983) é voltado para a aprendizagem em sala dos alunos e inclui, ainda, a avaliação diagnóstica, realizada ao início do semestre ou ano letivo.
} 
A cultura de avaliação do ensino é uma prática já consolidada nos países anglo-saxões. Países como os EUA possuem a avaliação da qualidade do ensino ou da docência desde a década de 1920 (Sobrinho, 2003). Há muitas metodologias, instrumentos e pesquisas a respeito do assunto, tratado de forma mais objetiva e analítica (Lucas et al., 1997; Marsh, 1984; Ramsden, 1991). No continente europeu, essa prática é mais recente, mas vem crescendo desde a Declaração de Bolonha (Morais, Almeida e Montenegro, 2006). Portugal apresentou durante décadas uma situação semelhante à do Brasil, em que a avaliação do ensino não era prioridade. Muitas vezes até existiam tais avaliações, mas somente com o objetivo de cumprir procedimentos burocráticos, sem envolvimento real com o ensino ministrado. Tendo a consciência da importância da avaliação do ensino, atualmente o país tem buscado pesquisar e implementar essas avaliações em nível nacional (Fernandes, 2008; Morais, Almeida e Montenegro, 2006).

No Brasil, não há uma tradição de avaliação formal do ensino ou da docência. Porém, tanto disciplinas quanto professores costumam ser avaliados informalmente dentro de cada curso superior, seja pelos alunos ou pelos próprios colegas. Em algumas universidades onde a autoavaliação é institucionalizada há avaliações de disciplinas disponíveis, mas estas são eletivas e utilizadas de acordo com o interesse do docente ou do curso a que a disciplina pertence. Nesses casos, a avaliação dificilmente ocorre sem a presença dos alunos. Atualmente, o Sistema Nacional de Avaliação do Ensino Superior (SINAES) enfatiza a necessidade da autoavaliação dos cursos e deixa em aberto a definição dos critérios, para que os próprios cursos possam definir suas prioridades. O objetivo é que essa autoavaliação gere informações - inclusive relacionadas ao ensino que promovam melhorias dentro de cada curso (SINAES, 2003).

A carência de avaliação da docência está relacionada com algumas características da universidade brasileira. Aqui, de modo geral, a carreira docente requer um título de doutorado que, por sua vez, é realizado dentro dos programas de pós-graduação (PPGs). Diferentemente da graduação, que possui o foco no ensino, a pós-graduação possui o foco na pesquisa, e é para ela que os doutores são formados. Nos PPGs, embora haja exceções, são escassas as atividades visando a docência - exceto pela disciplina de estágio docente, presente na maioria dos cursos, onde o aspirante a mestre ou doutor ministra aulas sob acompanhamento e avaliação do seu orientador. Embora seja essencial que o ensino se dê também através da pesquisa, na formação não há essa ênfase, pois a formação de doutores, majoritariamente, não se relaciona com a formação de professores. Entretanto, ao ingressar na universidade, o recém-admitido terá que estar pronto para assumir tanto a pesquisa quanto a docência, tendo sido preparado apenas para a primeira.

Durante a carreira, a avaliação dos docentes também acaba sendo direcionada para a pesquisa, pois a maioria deles deseja participar de PPGs como pesquisador e contribuir com o seu trabalho para produção de conhecimento. Para isso, entretanto, necessitam adaptar-se aos critérios estabelecidos pelos PPGs, que, por sua vez, seguem os indicadores de avaliação da produção intelectual utilizados pelas agências financiadoras da pós-graduação (CAPES, 2016). Logo, para o professor, esses critérios funcionam como metas, que podem ou não ser alcançadas, mas que são determinantes para a sua inserção ou permanência dentro dos PPGs. Portanto, pode-se considerar como uma avaliação informal, pois embora não influencie o plano de carreira de professores de universidades públicas, é ela que estratifica os docentes e garante a distribuição de recursos para os melhores, numa tentativa de qualificar a pesquisa científica brasileira. 
Essa avaliação tem sido discutida no meio acadêmico devido às limitações que envolvem a pesquisa no País, como escassez de recursos e qualidade da estrutura e, também, devido ao envolvimento dos docentes em outras atividades, como o ensino, fato que reduz o tempo dedicado à pesquisa e dificulta o alcance dos parâmetros de produção (Horta e Moraes, 2005; Kuenzen e Moraes, 2005).

Formar para a docência é um processo complexo pois o ensino envolve muitas atividades. Braskamp e Ory (1994), propuseram uma classificação destas baseadas em informações de professores e encontraram:

$\checkmark$ O ensino propriamente dito, feito das disciplinas, laboratórios, clínicas, etc.

$\checkmark$ A atividade de orientação e supervisão dos alunos que inclui os trabalhos em sala de aula mas também os de campo, a orientação individual, as atividades de laboratório, o aconselhamento sobre a profissão e a carreira, as orientações de trabalhos finais, dissertações e teses.

$\checkmark$ O desenvolvimento das atividades de aprendizagem, que compreende o planejamento e definição de quais atividades pedagógicas seriam mais adequadas àquele conteúdo, como organização dos cursos, materiais de ensino, manuais, consulta à literatura, etc.

$\checkmark$ Atividades promotoras do desenvolvimento profissional do docente, como participação em cursos e atualizações, avaliação do ensino de outros colegas e pesquisa no ensino.

O volume de atividades é grande e variável tanto entre os docentes quanto entre instituições. Mas, grosso modo, a maioria dos professores que atuam no ensino superior não recebe formação para tais funções (Costa, 2009). Para muitos, a única experiência como docente deu-se durante o período em que eram alunos e aprendiam observando as atitudes dos seus professores. Devido a isso, o aprendizado da docência se dá realmente on the job, na prática diária.

A ausência de formação para o ensino não é uma realidade somente brasileira. Fullan (1993, p. 105), ao estudar essa questão nos Estados Unidos (EUA), chega à conclusão de que: "A formação de professores tem a honra de ser a melhor solução e o pior problema na educação de hoje". Conforme o autor, existe muita retórica sobre a importância do professor, mas a sociedade ainda não tentou utilizar seriamente a formação de professores como uma ferramenta para a melhoria da qualidade do ensino. Segundo ele, parece que muitos líderes acreditam que ensinar não é difícil e que os professores aprendem na prática, como se houvesse certa desconfiança de que o investimento na formação de professores realmente produza resultados (Fullan, 1993).

Avaliar o ensino, considerando a ampla gama de atividades envolvidas, não é uma tarefa fácil. Entretanto, há diversos modelos de avaliação que podem ser escolhidos de acordo com o interesse do curso ou instituição. Cada um possui suas vantagens e limitações. A avaliação pelos alunos é o método mais comum, e será abordado com maior profundidade no próximo tópico. Um tipo de avaliação pelos pares consiste em um docente assistindo e avaliando a aula de outro docente, através de critérios pré-definidos. As limitações desse modelo referem-se às características quantitativas do processo e à difícil definição de critérios, que podem ou não incluir aspectos considerados importantes pelo docente 
avaliado. Porém, ainda na avaliação pelos pares, há um modelo que inclui avaliação através de portfólios, autoavaliações e relatos de experiências que tem sido mais aceito pelos docentes. Por ter características mais qualitativas, permite a ampla expressão de ideias e conceitos que envolvem o ensino; contudo, a limitação desse modelo refere-se à possibilidade de consideração de todas as situações como adequadas ou aceitáveis, o que dificulta uma avaliação posterior. (Herrera et al., 2012). Para que as ações possuam credibilidade, a escolha da forma de avaliação requer dos envolvidos um acordo sobre os principais critérios de qualidade e a definição de um número mínimo de indicadores mensuráveis para isso (Depresbiteris, 2008). Além disso, independentemente do instrumento escolhido, é sugerido que ele não seja único no processo. As avaliações devem incluir, preferencialmente, tanto alunos quanto professores e características tanto somativas quanto formativas (Depresbiteris, 2008; Dias Sobrinho, 2004; Fernandes, 2008).

\section{Avaliação do ensino pelos alunos}

A avaliação do ensino pelos alunos é considerada como um importante indicador de qualidade. As universidades, via de regra, direcionam suas avaliações para eles. No Brasil, o SINAES também sinaliza para essa direção (SINAES, 2003) ao orientar a autoavaliação das instituições de ensino superior. Os estudantes são considerados os sujeitos de aprendizagem, e, portanto, ninguém melhor do que eles para avaliar a qualidade do ensino (Marsh e Roche, 1994; Ramsden, 1991).

Uma avaliação feita pelos alunos pode trazer uma série de benefícios para o ensino. Primeiramente, ela permite que o professor conheça quais são os pontos fortes e fracos na sua prática pedagógica e pode estimulá-lo a aperfeiçoar a sua atividade. Ela pode inclusive, nortear os docentes iniciantes que não possuem uma formação específica para o ensino. Mas ela vai além. Marsh (1984) descreveu outras quatro finalidades que podem beneficiar as instituições: poder diagnosticar e retroalimentar a instituição sobre a efetividade do seu corpo docente; quantificar a efetividade do docente tendo em vista a sua promoção; prover informação aos estudantes buscando orientá-los na seleção de disciplinas e propiciar atividades de pesquisa em educação. Bittencourt et al. (2011) ressaltam que, destas quatro, a primeira finalidade descrita é a mais frequente nas IES brasileiras, mas que o caráter sigiloso e eletivo das avaliações faz com que a segunda e a terceira finalidades sejam pouco adotadas no País.

Apesar de serem termos relacionados, é necessário fazer uma distinção entre qualidade dos professores e qualidade do ensino. Para Darling-Hammond (2007), a qualidade dos professores pode aumentar a probabilidade de um ensino de qualidade, mas não o garante por si só. Ao investigar a eficácia docente, a autora identificou uma série de qualidades presentes nos professores que influenciam positivamente o ensino: inteligência e habilidade verbal para comunicar; domínio do conteúdo; conhecimento pedagógico do seu conteúdo; saber como ensinar os outros nessa área; a compreensão dos alunos, da sua aprendizagem e do seu desenvolvimento; ser um "especialista/expert adaptativo" que permite ao professor julgar sobre o modo como deve agir em determinado contexto para responder às necessidades dos alunos. Segundo a autora, a qualidade do professor está relacionada às suas características pessoais, habilidades e entendimentos que são levados para o ensino e que podem ser aperfeiçoadas. 
Já a qualidade do ensino, inclui, além da qualidade do professor, o contexto e as condições de ensino (Darling-Hammond, 2007). Resumidamente, uma equação poderia descrevê-la assim:

Qualidade do ensino $=$ Qualidade do docente + contexto e condições de ensino.

Isso significa que um professor de "alta qualidade" pode não ser capaz de oferecer o ensino de alta qualidade num contexto em que há incompatibilidade entre o seu conhecimento e a demanda da instituição. Por exemplo, quando um professor assume disciplinas que são afastadas da sua área de formação/especialização, ou quando assume muitas disciplinas concomitantemente. Nesses casos, não há um contexto de ensino apropriado para que o professor exerça a sua "alta qualidade". Assim, um professor de alta qualidade em uma circunstância pode não ser um professor de alta qualidade para o outro. Outra questão destacada pela autora diz respeito às condições do ensino. A qualidade do ensino pode ser prejudicada se um professor de qualidade não dispuser no seu cotidiano de materiais curriculares adequados, equipamentos necessários, número de alunos compatível com as atividades, oportunidades para planejamento com os demais colegas, etc. Muitas destas condições estão fora do controle dos professores, ficando sob a responsabilidade dos sistemas político e administrativo da instituição (DarlingHammond, 2007). Por esses motivos, o contexto e as condições de ensino devem ser considerados durante a análise dos resultados de avaliações do ensino.

Pelo viés do aluno, as atividades docentes possuem diferentes valores. Nessa linha, muitos autores têm se dedicado a estudar quais dimensões são consideradas por eles como positivas no processo de aprendizagem (Cohen, 1980; Feldman, 2007; Marsh, 1984). Alguns resultados destes estudos são apresentados no Quadro 1. Cohen (1980) realizou uma meta-análise para comparar e integrar resultados de 22 estudos sobre a eficácia da avaliação dos alunos na melhoria da educação e encontrou algumas dimensões predominantes. Já Feldman (2007) estudou como as avaliações dos estudantes podem ser usadas para identificar aquelas pessoas que são vistas por eles como professores exemplares e como esse ensino exemplar pode ser identificado através dessas avaliações. Ele identificou 28 dimensões associadas ao aprendizado dos alunos, mas verificou que algumas são mais importantes do que as outras. Por sua vez, Marsh (1984), ao realizar um trabalho com mais de 500 mil estudantes, encontrou nove dimensões associadas ao ensino de qualidade, que, posteriormente, foram transportadas para o questionário de avaliação Students Evaluation Educational Quality (SEEQ). Observa-se que, nas dimensões encontradas pelos três autores, o professor aparece como um elemento essencial, pois os elementos indicados pelos estudantes dependem direta ou indiretamente da atividade deste.

É reconhecido que há uma influência do professor sobre os alunos. Essa influência pode ser tanto positiva, estimulando o desenvolvimento dos alunos, quanto negativa, estagnando esse desenvolvimento. Qualquer reforma educacional depende de um corpo docente altamente qualificado. Seja durante a mudança de currículos ou no uso de diferentes estratégias de ensino, têm sido constatado que os professores são a base, o ponto de sustentação que determina se alguma inciativa da escola irá em direção ao sucesso ou ao fracasso (Darling-Hammond, 2007).

Muitos professores, entretanto, são resistentes a avaliações do ensino pelos alunos. Chonko, Tanner e Davis (2002) organizaram algumas das razões relatadas por docentes 
sobre os motivos que levam à oposição a esse tipo de avaliação: i) o receio de que essas informações sejam usadas como única forma de avaliação de desempenho por parte da administração; ii) a penalização do professor por parte de alunos que não conseguem bom desempenho na disciplina; iii) vingança dos alunos por motivos variados; iv) alguns docentes vêem a avaliação como uma competição por popularidade e que pouco avalia o seu conhecimento científico; e v) percepção dos docentes de que os alunos possuem conhecimentos insuficientes para avaliar a qualidade do ensino. Na maioria das vezes, as críticas referem-se às avaliações do tipo somativas. Conforme os professores, esse grande número de variáveis poderia influenciar os resultados a ponto de inviabilizar a avaliação. Todavia, observa-se que a maioria dos professores possui uma atitude mais favorável à avaliação do tipo formativa, pois consideram que esta trata individualmente cada docente e pode contribuir positivamente para a melhoria do seu desempenho (Fernández, Sánchez e García, 1996).

Quadro 1. Dimensões consideradas como positivas no processo de aprendizagem, na visão de estudantes

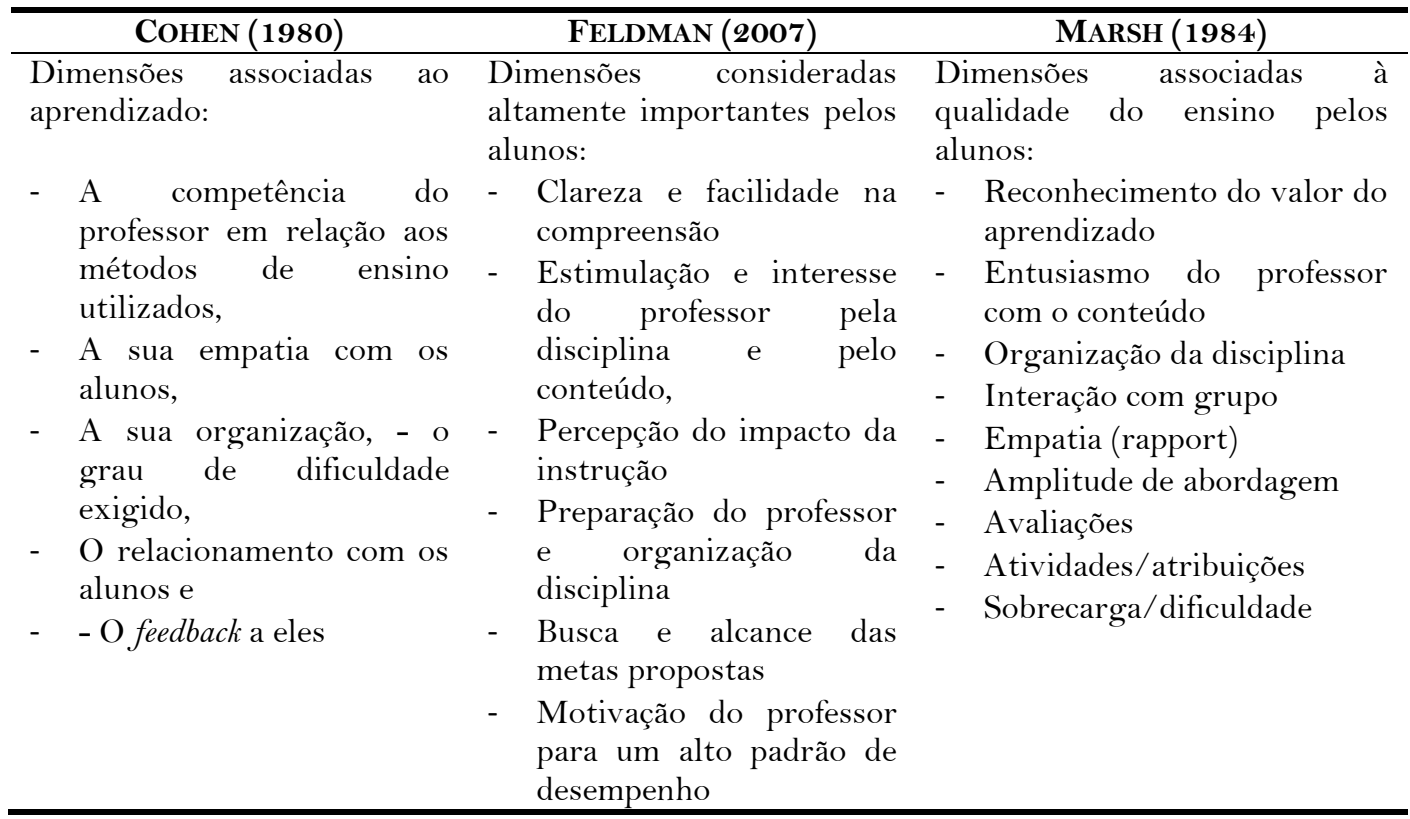

Fonte: Elaboração própria.

Na tentativa de esclarecer a polêmica em torno da avaliação do ensino pelos alunos, Marsh (1984) pesquisou quais eram os fatores que realmente influenciavam as respostas dos alunos. Os principais achados foram: o interesse prévio do aluno na disciplina, a sua nota atual ou esperada, os motivos pelos quais se matriculou, a carga de trabalho e dificuldade e o tamanho da turma. E há o chamado "efeito Dr. Fox", que diz que a desenvoltura do professor influencia nas respostas dos alunos. Neste trabalho (Naftulin, Ware e Donnelly, 1973) houve a contratação de um ator para ministrar uma aula como professor bastante desenvolto, porém sem conteúdo. Curiosamente, a avaliação dos alunos em relação à aprendizagem foi positiva. Este trabalho, apesar de ser criticado metodologicamente, traz à tona a discussão sobre a influência do estilo na avaliação dos alunos. Porém, o próprio Marsh (1984) reconhece que os efeitos dessas variáveis sobre os resultados quantitativos tende a ser pequeno e que não se justifica uma ausência de avaliação face às dificuldades que ela envolve. Além disso, é necessário reconhecer a 
necessidade de dar voz aos alunos. A avaliação deve ser o meio que permite que o estudante se comunique com o curso sobre questões relacionadas ao ensino.

Tomando como modelo as experiências de outros países, em Portugal, por exemplo, durante décadas os esforços para melhorias dos sistemas educativos foram concentrados nas melhorias dos currículos, nos processos de gestão e no desenvolvimento de novos programas de ensino (Fernandes, 2008). O Brasil atual passa por um processo semelhante (Costa et al., 2013. Garcia e Silva, 2010; Vieira e Tamousauskas, 2013). Entretanto, atualmente essa visão é considerada ingênua, pois a experiência demonstrou que a simples mudança de currículos ou de programas não melhora a qualidade da educação (Darling-Hammond, 2007; Fernandes, 2008). Já há o entendimento de que é preciso melhorar a qualidade do trabalho pedagógico e dos sistemas de apoio à aprendizagem para melhorar a qualidade do ensino, e os responsáveis por essa prática são os professores (Fernandes, 2008). Logo, numa avaliação do ensino pelos alunos, a figura do professor será, direta ou indiretamente, também avaliada. Como não há como separar o professor do ensino, também não há como separá-lo da avaliação do ensino.

\section{Situação atual da avaliação do ensino pelos alunos no Brasil}

No SINAES, a avaliação do ensino está inserida, implicitamente, dentro do quesito autoavaliação (Figura 1). Implicitamente porque não há a proposição de um modelo, nem tampouco de critérios para esta autoavaliação, pois o SINAES considera que estes devem ser desenvolvidos por cada curso ou instituição, garantindo a sua autonomia. Durante as avaliações dos cursos superiores o SINAES somente avalia a existência dessa autoavaliação, verifica se está implementada e se os resultados foram utilizados para o aperfeiçoamento do curso. A nota máxima de 5 é alcançada quando "os mecanismos de autoavaliação apresentam excelente funcionamento, e constata-se a implementação efetiva de ações acadêmico-administrativas em decorrência dos relatórios produzidos pela autoavaliação e pela avaliação externa". As autoavaliações dos cursos, via de regra, incluem uma avaliação de cada disciplina para que o ensino possa ser avaliado independentemente.

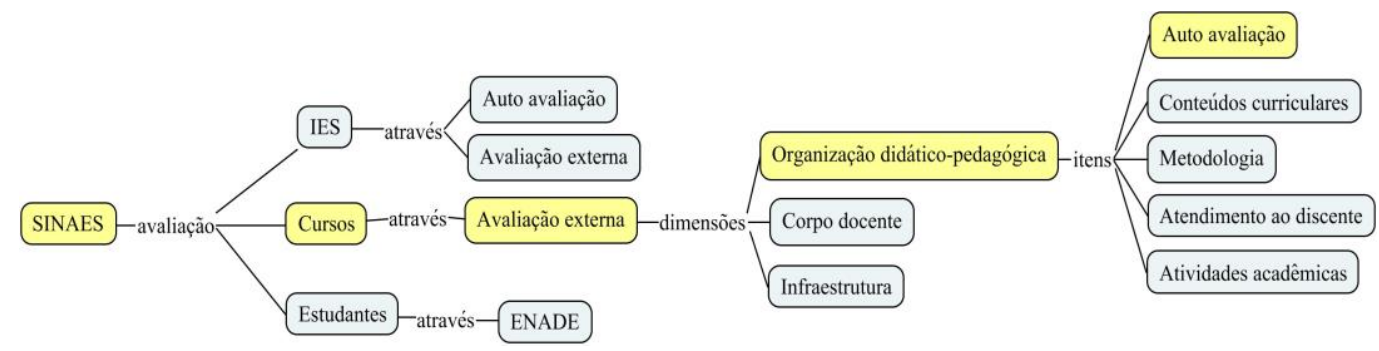

Figura 1. Elementos avaliados pelo SINAES

Fonte: Elaboração própria.

Apesar de ainda serem escassas as pesquisas em torno desse tema, há algumas instituições que já publicaram artigos sobre o desenvolvimento de seus instrumentos de avaliação do ensino pelos alunos. Bittencourt et al. (2011) elaboraram e validaram um questionário de avaliação de disciplinas para a Pontifícia Universidade Católica do Rio 
Grande do Sul e o dividiram em três dimensões: aspectos gerais da disciplina, ação de ensino do professor e autoavaliação. Com o trabalho foi demonstrado que o instrumento possuía as características psicométricas desejáveis relacionadas à sua validade e fidedignidade. A validação é um processo importante, pois avalia se o instrumento pode ter ou não as suas respostas consideradas como válidas. Grosso modo, avalia se o instrumento mede o que se propõe a medir. Entretanto, ela não é um processo comum na avaliação de disciplinas no Brasil. A maioria dos questionários utilizados em universidades brasileiras - muitos estão disponíveis na internet - não passa pelo processo de validação, são somente planejados e executados pela gestão dos cursos de graduação.

\section{Instrumentos de avaliação}

Para desenvolver a avaliação da docência ou do ensino pelos alunos, a metodologia mais amplamente utilizada é o questionário, pois ele evita a interação direta entre o pesquisador e os alunos e é útil, principalmente, quando se pretende questionar um grande número de pessoas em um curto intervalo de tempo. As limitações do uso desses instrumentos dizem respeito às interpretações diferentes sobre as questões e a não garantia do preenchimento destas, o que pode reduzir a representatividade da amostra (Gil, 1999). Além, obviamente, a crítica sobre o viés quantitativo dos questionários. Entretanto, reitera-se que, para ser utilizado como fonte de retroalimentação sobre o ensino das instituições, ele não deve ser a única fonte de informação, mas sim fazer parte de uma gama de instrumentos diversos e complementares de avaliação (Depresbiteris, 2005; Estrela e Simão, 2003). Destaca-se que a limitação relacionada às diferentes interpretações é reduzida ao máximo através do processo de validação de questionários.

No âmbito internacional, a avaliação do ensino ou da docência é realizada, principalmente, através de instrumentos conhecidos como Student Evaluation of Teaching (SETs). São questionários que possuem as características de serem multidimensionais, reprodutíveis e estáveis. Eles são relativamente válidos para uma variedade de indicadores de efetividade de ensino e relativamente não afetados por uma variedade de variáveis tidas como potenciais vieses, sendo considerados úteis para fornecer um feedback sobre o ensino (Marsh, 1982, 1984, 2007; Marsh e Dunkin, 1992).

Há diversos modelos validados fora do Brasil e alguns merecem destaque devido às suas particularidades:

$\checkmark$ Course Experience Questionnaire (CEQ): O CEQ foi desenvolvido por Ramsden (1991) e avalia as experiências dos estudantes quanto à qualidade dos programas de aprendizado, como o curso inteiro. A versão original foi revisada em 2002 e contêm 25 itens, que abrangem: bom ensino, objetivos e padrões claros, dificuldade e sobrecarga adequados, avaliações apropriadas e ferramentas genéricas. Os estudantes avaliam sua concordância através de uma escala Likert de 5 pontos. É utilizado em diversas universidades na Austrália e na Irlanda.

$\checkmark$ Module Experience Questionnaire (MEQ): É uma modificação do CEQ realizado por Lucas et al. (1997) que explora os efeitos da presença ou da ausência de módulos de ensino, bem como a influência do tamanho deles no aprendizado. As escalas do MEQ são: bom ensino, objetivos e padrões claros, carga de 
trabalho adequada, avaliações apropriadas, independência dos estudantes e aprofundamento da abordagem.

$\checkmark$ Experiences of Teaching and Learning Questionnaire (ETLQ) e Learning and Studying Questionnaire (LSQ): Ambos foram desenvolvidos como parte do projeto Enhancing Teaching-Learning Environments in Undergraduate Courses, desenvolvido entre três universidades do Reino Unido. Eles avaliam a percepção dos estudantes sobre o ambiente de ensino e aprendizagem e suas abordagens para o estudo em cada curso ou disciplina.

$\checkmark$ Students' Evaluation of Educational Quality (SEEQ): Desenvolvido por Marsh, 1984) apresenta 35 questões sobre 9 dimensões relacionadas à efetividade do ensino: valor, entusiasmo, organização, interação como grupo, empatia/rapport, amplitude do conhecimento, exames, avaliações e dificuldade. O SEEQ é utilizado em mais de 500 universidades no mundo (Coffey e Gibbs, 2000; Marsh, 1984; Marsh e Roche, 1992) e tem sua validade e reprodutibilidade têm sido confirmadas internacionalmente (Coffey e Gibbs, 2000; Marsh e Roche, 1992).

Todos os modelos de questionários tiveram por objetivo reunir aspectos considerados importantes no ensino na visão de alunos. Ao serem utilizados integral ou parcialmente, podem facilitar o trabalho das instituições que possuem interesse em avaliar a qualidade do seu ensino.

\section{Considerações finais}

A discussão em torno da avaliação do ensino tem sido influenciada por abordagens epistemológicas que põem, de um lado, o quantitativo e, do outro, o qualitativo. É necessário ressaltar que ambas devem aceitas e incluídas, pois tanto a subjetividade intrínseca ao processo de ensino quanto a garantia da objetividade necessária a uma avaliação, são importantes no processo de avaliação. Antes de se contraporem, elas devem complementar-se uma a outra, na tentativa de ampliar as concepções de ensino dentro de cada avaliação.

No Brasil, a carência de avaliação de ensino perpassa pela ausência de tradição na área e pelas características do processo de formação de professores universitários. As agências financiadoras dos PPGs possuem indicadores de qualidade que acabam por direcionar o perfil dos professores para a pesquisa, distanciando, assim, do ensino. Avaliar o ensino não é uma tarefa fácil, pois a definição de critérios deveria incluir toda a gama de atividades docentes, e esta é bastante variável entre áreas e instituições. No entanto, as dificuldades do processo não justificam a sua não realização.

No caso específico de avaliação pelos alunos, ela é a garantia de que a instituição está dando voz a seus estudantes. Para ouvi-los em grande número, não há instrumento mais amplamente aplicável do que os questionários. Há diversos modelos utilizados internacionalmente que conseguiram alcançar muitas dimensões associadas ao processo de ensino. Mesmo se não utilizados integralmente, eles podem subsidiar o trabalho dos docentes na definição das dimensões mais importantes para cada instituição e/ou curso de graduação. 
A avaliação do ensino pelos alunos pode seguir dois caminhos: ou transformar-se em uma atividade burocrática em que os resultados são ignorados tanto por alunos quanto pelos próprios professores, ou então ser um processo voltado ao aperfeiçoamento contínuo do ensino e da docência. Definir os propósitos que se pretendem alcançar com a avaliação é essencial, pois os instrumentos escolhidos devem tentar atendê-los.

\section{Referências}

Bittencourt, H. R., Creutzberg, M., De Morais Rodrigues, A. C., Casartelli, A. O. e Freitas, A. L. S. (2011). Desenvolvimento e validação de um instrumento para avaliação de disciplinas na educação superior. Estudos em Avaliação Educacional, 22(48), 91-113. doi:10.18222/eae224820111994

Bobbio, N. (1992) A era dos direitos. Rio de Janeiro: Campus/Elsevier.

Bloom, B. S. (1983). Manual de avaliação formativa e somativa do aprendizado escolar. São Paulo: Pioneira Editora.

Brandalise, M. A. T. (2010). Avaliação institucional da escola: Conceitos, contextos e práticas. Olhar de Professor, 13(2), 317-332. doi:10.5212/olharprofr.v.13i2.0008

Brasil. (2004). Lei $n^{\circ} .10 .861$, de 14 de abril de 2004. Institui o Sistema Nacional de Avaliação da Educação Superior - SINAES.

Braskamp, L. A. e Ory, J. C. (1994). Assessing faculty work: Enhancing individual and institutional performance. San Francisco, CA: Jossey-Bass Inc.

Coordenação de Aperfeiçoamento de Pessoal de Nível Superior (CAPES). (2016). Permanência no Sistema Nacional de Pós Graduação - Acompanhamento e avaliação trienal. Disponível em http://cartadeservicos.capes.gov.br

Chonko, L. B., Tanner, J. F. e Davis, R. (2002). What are they thinking? Students' expectations and self-assessments. Journal of Education for Business, 77(5), $271-281$. doi:10.1080/08832320209599676

Coffey, M. e Gibbs, G. (2000). The evaluation of the student evaluation of educational quality (SEEQ) questionnaire in UK higher education. Assessment and Evaluation in Higher Education, 26(1), 89-93. doi:10.1080/02602930020022318

Cohen, P. A. (1980). Effectiveness of student rating feedback for improving college instruction. A metaanalysis of multisection validity studies. Research in Higher Education, 13(4), 321-341. doi: $10.1007 /$ bfoog76252

Costa, E. Q., Domingues, J. R., Malheiros, L. R. e Jardim, M. F. B. (2013). Desafios à reforma curricular em um curso de graduação em nutrição. Demetra, 8(3), 469-485. doi:10.12957/demetra.2013.6210

Costa, N. M. C. (2009). Formação pedagógica de professores de nutrição: Uma omissão consentida? Revista de Nutrição, 22(1), 97-104. doi:10.1590/s 1415-52732009000100009

Darling-Hammond, L. (2007). Recognizing and enhancing teacher effectiveness: A policy maker's guide. Em L. Darling-Hammond e C. D. Prince (Eds.), Strengthening teacher quality in highneed schools—policy and practice (pp. 1-26). Washington DC: Council of Chief State School Officers 
Depresbiteris, L. (2005). Auto-avaliação das instituições de ensino superior. Estudos em Avaliação Educacional, 16(32), 7-24. doi:10.18222/eae163220052133

Hounsell, D., Entwistle, N., Anderson, C., Bromage, A., Day, K., Hounsell, J., Land, R., Litjens, J., McCune, V., Meyer, E., Reimann, N. e Xu, R. (2005). Enhancing teaching-learning environments in undergraduate courses. Final Report to the Economic and Social Research Council on TLRP Project L. Disponível em http://www.etl.tla.ed.ac.uk/docs/ETLfinalreport.pdf

Estrela, M. T. e Simão, A. M. V. (2003). Algumas reflexões sobre práticas de avaliação do ensino universitário e dos docentes a partir da informação recolhida no Projecto EVALUE. Revista Portuguesa de Educação, 16(1), 101-120.

Feldman, K. A. (2007). Identifying exemplary teachers and teaching: Evidence from student ratings. Em R. P. Perry e J. C. Smart (Eds.), The scholarship of teaching and learning in higher education: An evidence-based perspective (p. 93-143). Houten: Springer Netherlands.

Fernandes, D. (2008). Avaliação do desempenho docente: Desafios, problemas e oportunidades. Lisboa: Texto Editores.

Fernández, J. M., Sánchez, J. F. e García, M. A. M. (1996). Valoración por parte del profesorado de la evaluación docente realizada por los alumnos. Psicothema, 8(1), 167-172.

Franco, M. L. P. B. (1990). Pressupostos epistemológicos da avaliação educacional. Cadernos de Pesquisa, 74, 63-67.

Fullan, M. (1993). Change forces: Probing the depths of educational reform. Levittown, PA: Psychology Press.

Garcia, M. A. A. e Silva, A. L. B. (2011). Um perfil do docente de Medicina e sua participação na reestruturação curricular. Revista Brasileira de Educação Médica, 35(1), 58-68. doi:10.1590/s0100-55022011000100009

Gil, A. C. (1999). Métodos e técnicas de pesquisa social. São Paulo: Atlas.

Herrera, F., Cano, M. Á., Hernández, L. y Morales, M. A. (2012). Sistema de evaluación del desempeño profesional docente para las licenciaturas del área de las ciencias biológicas y de la salud. RIEE. Revista Iberoamericana de Evaluación Educativa, 5(2), 124-146.

Horta, J. S. B e Moraes, M. C. M. (2005). O sistema CAPES de avaliação da pós-graduação: Da área de educação à grande área de ciências humanas. Revista Brasileira de Educação, 30(4), 95-116.

Kuenzer, A. Z. e Moraes, M. C. M. (2005). Temas e tramas na pós-graduação em educação. Educação छ̊ Sociedade, 26(93), 1341-1362. doi:10.1590/s0101-73302005000400015

Lucas, L., Gibbs, G., Hughes, S., Jones, O. e Wisker, G. (1997). A study of the effects of course design features on student learning in large classes at three institutions: A comparative study. Em C. Rust e G. Gibbs (Eds.), Improving student learning: Improving student learning through course design (pp. 10-24). Oxford: Oxford Centre for Staff and Learning Development.

Marsh, H. e Roche, L. (1992). The use of student evaluations of university teaching in different settings: The applicability paradigm. Australian Journal of Education, 36(3), 278-300. doi:10.1177/000494419203600305

Marsh, H. W. e Dunkin, M. J. (1992). Students' evaluation of university teaching: A multidimensional perspective. Em J. C. Smart (Ed.), Higher education: Handbook of theory and research (Vol. 8) (pp. 143-234). Nueva York: Agathon. 
Marsh, H. W. e Roche, L. A. (1997). Making student's evaluations of teaching effectiveness: The critical issues of validity, bias and utility. American Psychologist, 52(11), 1187-1197. doi:10.1037/0003-066x.52.11.1187

Marsh, H. W. (1982). SEEQ: A reliable, valid, and useful instrument for collecting students' evaluations of university teaching. British Journal of Educational Psychology, 52(1), 77-95. doi: $10.1111 /$ j.2044-8279.1982.tb02505.x

Marsh, H. W. (1984). Student's evaluations of university teaching: Dimensionality, reliability, validity, potential biases and utility. Journal of Educational Psychology, 76(5), 707-754. doi:10.1037/0022-0663.76.5.707

Marsh, H. W. (2007). Students evaluations of university teaching: Dimensionality, reliability, validity, potential biases and usefulness. Em R. P. Perry y J. C. Smart (Eds.), The scholarship of teaching and learning in higher education: An evidence-based perspective (pp. 319383). Houten: Springer Netherlands.

Morais, N., Almeida, L. e Montenegro, I. (2012). Percepções do ensino pelos alunos: Uma proposta de instrumento para o Ensino Superior. Análise Psicológica, 24(1), 73-86. doi:10.14417/ap.155

Naftulin, D. H, Ware, J. E e Donnelly, F. A. (1973). The Doctor fox lecture: A paradigm of educational seduction. Journal of Medical Education, 48(7), 630-635. 10.1097/00001888197307000-0003

Ramsden, P. (1991). A performance indicator of teaching quality in higher education: The course experience questionnaire. Studies in Higher Education, 16(2), 129-150. doi:10.1080/03075079112331382944

Scriven, M. (1966). The methodology of evaluation. Social Science Education Consortium, Publ. 110. Boulder, CO: University of Colorado.

SINAES (Sistema Nacional de Avaliação do Ensino Superior). (2003). Bases para uma nova proposta de avaliação do ensino superior. Brasil: Ministério da Educação.

Sobrinho, J. D. (2004). Avaliação ética e política em função da educação como direito público ou como mercadoria. Educação e Sociedade, 25(88), 703-725. doi:10.1590/s01017330200400300004

Sobrinho, J. D. (2003). Avaliação: Políticas educacionais e reformas da educação superior. São Paulo: Cortez.

Vieira, J. E. e Tamousauskas, M. R. G. (2013). Avaliação das resistências de docentes a propostas de renovações em currículos de Graduação em Medicina. Revista Brasileira de Educação Médica, 37(1), 32-38. doi:10.1590/s0100-55022013000100005

\section{Breve CV de los autores}

\section{Joice Trindade Silveira}

Docente do curso de Nutrição na Universidade Federal do Pampa (UNIPAMPA), na área de Gestão de Unidades de Alimentação e Nutrição e Deontologia. Possui graduação em Nutrição e Mestrado em Microbiologia Agrícola e do Ambiente pela Universidade Federal do Rio Grande do Sul (UFRGS). É estudante de doutorado no PPG Educação em Ciências - Química da 
vida e saúde na UFRGS, desenvolvendo trabalhos na área de avaliação de disciplinas e professores. E-mail: joicetsilveira@gmail.com

\section{João Batista Teixeira da Rocha}

Possui Graduação em Ciências Biológicas pela Universidade Federal do Rio Grande do Sul - UFRGS (1986), e Doutorado em Ciências Biológicas (Bioquímica) pela Universidade Federal do Rio Grande do Sul - UFRGS (1996). Realizou seu Pós-Doutorado na UFRJ, Departamento de Bioquímica Médica no Laboratório de Bioenergética coordenado pelo Prof. Leopoldo de Meis (19971998). Atualmente trabalha na área de bioquímica, toxicologia e farmacologia de organocalcogênio, papel do estresse oxidativo em patologias humanas e experimentais e educação em ciências. Têm experiências na área de toxicologia, sistema nervoso central (incluindo psicofarmacologia e desenvolvimento), farmacologia de organocalcogênios e interação entre calcogênios e tióis. Participa de atividade relacionados ao ensino de ciências e como melhorar o ensino de ciências por meio da interação entre cientistas e estudantes e professores do ensino médio e fundamental. 